\title{
Economic Study on the Impact of Side Effects in Patients Taking 0xycodone Controlled-Release for Noncancer Pain
}

\author{
Kathryn P. Anastassopoulos, MS; Wing Chow, MPH, PharmD; Crisanta I. Tapia, MHS; \\ Rebecca Baik, BS; Stacey J. Ackerman, MSE, PhD; David Biondi, DO; and Myoung S. Kim, MBA, PhD
}

\begin{abstract}
BACKGROUND: Chronic pain is a prevalent condition in the United States. Musculoskeletal pain, including joint and back pain, is the most common type of chronic pain, and many patients with back pain have a neuropathic component. Pain has direct economic consequences. While oxycodone controlled-release (CR) is one of the most widely used oral long-acting opioids for pain, including pain with a neuropathic component, it is often associated with bothersome side effects, resulting in additional medical resource use (MRU) and costs.
\end{abstract}

OBJECTIVE: To examine the impact on MRU and costs to payers of side effects in patients taking oxycodone CR alone or in combination with other pain medications for noncancer pain (including those with neuropathic pain symptoms).

METHODS: A nationwide convenience sample of adults in the United States, who participated in a survey research panel and reported current use of oxycodone CR for noncancer pain, completed an online survey between November 2, 2010, and December 13, 2010. Respondents were excluded if they reported current use of other extended-release or long-acting opioid prescription medications. The survey consisted of questions on demographics, clinical characteristics, pain characteristics, experience with pain medication, and MRU associated with side effects. Payer costs were calculated based on the MRU reported by the respondents multiplied by Medicare reimbursement rates for hospitalizations and outpatient visits and average wholesale price (AWP) minus $20 \%$ for medications. A subgroup of patients who reported neuropathic pain symptoms also was examined.

RESULTS: After applying the exclusion criteria, 432 respondents completed the survey. Approximately half of the respondents $(n=219 ; 50.7 \%)$ reported neuropathic pain symptoms. The majority of respondents were Caucasian (88.4\%) and female (63.7\%) with an average age of 41.8 years (14.89). Respondents most frequently reported low back pain (41.2\%), followed by osteoarthritis/rheumatoid arthritis $(20.4 \%)$, neuropathic pain $(10.6 \%)$, and fibromyalgia (9.0\%). Respondents reported having their pain condition for an average of 5.4 (7.42) years. On days when taken, respondents reported a mean oxycodone CR daily dose of $83.3 \mathrm{mg}$ (126.93) taken in an average of 2 doses. Most respondents (82.4\%) reported experiencing at least 1 side effect with $77.5 \%$ being bothered by at least 1 side effect. The most frequently reported side effects (>25\%) were drowsiness $(41.4 \%)$, constipation (37.0\%), fatigue or daytime sleepiness (36.6\%), and dizziness $(27.1 \%)$. Among respondents who reported being bothered by one or more side effects in the previous month, MRU associated with side effects was reported by $39.1 \%$ of respondents and significantly increased as the level of side-effect bother increased from $19.8 \%$ among those "A little bit bothered" to $38.4 \%$ among those "Bothered" to $61.0 \%$ among those "Extremely bothered" $(P<0.001)$. Additionally, total average payer costs (in 2010 dollars) per respondent in the previous month associated with side effects were $\$ 238(\$ 1,159)$ and also significantly increased as the level of sideeffect bother increased from $\$ 61$ (\$512) among those "A little bit bothered" to $\$ 238(\$ 1,160)$ among those "Bothered" to $\$ 425(\$ 1,561)$ among those "Extremely bothered" $(P<0.001)$. Results reported in the neuropathic pain subgroup were similar to results reported in the total study sample.

CONCLUSIONS: Among adults taking oxycodone CR for chronic noncancer pain (with or without a neuropathic pain component), over three-fourths reported being bothered by side effects. Respondents who reported higher levels of side-effect bother also reported greater MRU, resulting in increased payer costs. The results of this study provide further support of the economic burden to payers associated with opioid-related side effects in patients with chronic noncancer pain, with and without neuropathic pain.

J Manag Care Pharm. 2012;18(8):615-26

Copyright $\odot 2012$, Academy of Managed Care Pharmacy. All rights reserved.

\section{What is already known about this subject}

- The Institute of Medicine (IOM) estimated that, in 2011, at least 100 million adults (almost half of the adult population) in the United States had chronic pain. Musculoskeletal pain, including joint and back pain, is the most common type of chronic pain. In addition, between $20 \%$ and $35 \%$ of patients with back pain also experience neuropathic pain (Freynhagen 2009).

- While extended-release opioids are recommended as part of a multimodal strategy for the management of chronic pain, they are often associated with side effects. Clinical trials of oxycodone controlled-release (CR) reported that approximately $23 \%$ of patients experienced constipation, nausea, and/or somnolence, and between 12\% and 13\% experienced dizziness, pruritus, and/or vomiting. One phase 3 trial found that $82 \%$ of patients, with chronic osteoarthritis or low back pain, taking oxycodone extended-release experienced at least one side effect (Friedmann 2011). Similarly, in a survey study of oxycodone immediaterelease use for noncancer pain, 84\% of respondents reported being bothered by side effects, with impact on their quality of life (Anastassopoulos 2011).

- Chronic pain can lead to increased medical resource use (MRU), imposing added costs to payers. One study estimated the incremental annual cost to U.S. society of medical care for headache, abdominal pain, chest pain, and back pain at $\$ 261$ to $\$ 300$ billion (IOM 2011). 


\section{What this study adds}

- This study evaluates the potential burden of side effects on patients and payers among adults taking oxycodone $\mathrm{CR}$, alone or in combination with other pain medications, for chronic noncancer pain and a subgroup of adults with neuropathic pain.

- The majority (82.4\%) of respondents reported experiencing at least 1 side effect, with $77.5 \%$ also being bothered by at least 1 side effect.

- More than half (54.9\%) of respondents reported taking oxycodone CR less than instructed. Among those, $40.9 \%$ stated that bothersome side effects were one of the primary reasons for not taking oxycodone $\mathrm{CR}$ as instructed.

- Respondents reported MRU associated with side effects that translated to average payer costs per respondent in the previous month of $\$ 238$ ( $\$ 1,159)$. These costs significantly increased as the level of side-effect bother increased from \$61 (\$512) among those "A little bit bothered" to $\$ 238(\$ 1,160)$ among those "Bothered" to $\$ 425(\$ 1,561)$ among those "Extremely bothered" $(P<0.001)$.

- Respondents with neuropathic pain reported MRU associated with side effects that translated to average payer costs per respondent in the previous month of $\$ 272(\$ 1,210)$. These costs significantly increased as the level of side-effect bother increased from $\$ 115$ (\$719) among those "A little bit bothered" to $\$ 253$ $(\$ 1,188)$ among those "Bothered" to $\$ 488(\$ 1,619)$ among those "Extremely bothered" $(P=0.001)$.

I n 2011, it was estimated that at least 100 million adults (almost half of the adult population) in the United States were affected by chronic pain. ${ }^{1}$ Musculoskeletal pain, including joint and back pain, is the most common type of chronic pain. ${ }^{2}$ Recent epidemiological studies have shown that between $20 \%$ and $35 \%$ of patients with back pain also experience neuropathic components, ${ }^{3}$ which are associated with more severe pain symptoms. ${ }^{4}$ Another study reported that back and neck pain with neuropathic involvement is probably the most frequent neuropathic pain disorder. ${ }^{5}$ A study that examined polypharmacy across categories of pain conditions (i.e., nociceptive, neuropathic, mixed, and osteoarthritis) found that use of the World Health Organization Analgesic Ladder Step III therapy and adjuvant pain medications were highest among those with neuropathic pain diagnoses. ${ }^{6}$ In addition, the percentage of days on Step III therapies was longest among patients with neuropathic pain diagnoses, increasing their risk for experiencing common long-term side effects from opioid use, such as constipation. ${ }^{7}$ In the United States, chronic pain is the most common reason for medical appointments. ${ }^{8}$ One study estimated the incremental annual cost to U.S. society of medical care for headache, abdominal pain, chest pain, and back pain at $\$ 261$ to $\$ 300$ billion, adjusted to 2010 dollars. ${ }^{1}$ Patients with a neuropathic pain component incur greater medical resource use (MRU) and associated costs. ${ }^{4}$

The American Society of Anesthesiologists Practice Guidelines for Chronic Pain Management recommend the use of extended-release opioids as part of a multimodal pain management strategy for patients with neuropathic pain or back pain. ${ }^{9}$ However, side effects associated with opioids have the potential to limit opioid use. ${ }^{10}$ Common side effects of opioid use include nausea, vomiting, constipation, dizziness, physical dependence, tolerance, and respiratory depression. ${ }^{11}$ The most common are constipation and nausea, which can be difficult to manage, particularly constipation. ${ }^{11}$ These side effects may lead to opioid discontinuation and underdosing, which then result in inadequate analgesia. ${ }^{11}$

Clinical trials of oxycodone controlled-release (CR) reported that approximately $23 \%$ of patients experienced constipation, nausea, and/or somnolence, and between 12\% and 13\% of patients experienced dizziness, pruritus, and/or vomiting. ${ }^{12}$ Clinical trials in oxycodone immediate-release (IR) reported similar side-effect profiles. ${ }^{12}$ One phase 3 trial reported that $82 \%$ of patients taking oxycodone extended-release, for chronic pain of the lower back or osteoarthritis of the hip and/or knee, experienced at least one side effect, the most common being constipation, nausea, and somnolence. ${ }^{13}$ Similarly, in a survey study of oxycodone IR use for noncancer pain (which excluded patients taking oxycodone CR), $84.0 \%$ of respondents reported being bothered by side effects, with impact on their quality of life. ${ }^{14}$

Although the use of opioids and the associated frequency of side effects have been documented in a number of studies, there is a general lack of published data on the economic burden of side effects in noncancer patients taking oxycodone $\mathrm{CR}$, including the effect on MRU and associated costs. One retrospective private-payer claims study examined the incremental 3-month cost for health care services in the United States among noncancer patients initiating oxycodone or hydrocodone-containing IR therapy, who experienced and had a claim for a gastrointestinal side effect. Among patients with a claim for nausea/vomiting and constipation, the average incremental 3-month cost, immediately following initiation, was $\$ 8,595$ per patient and $\$ 7,745$ per patient, respectively. ${ }^{15}$ Another retrospective claims study in 39,485 patients, with at least 30 days of opioid use, found significantly higher MRU and related all-cause costs among patients with constipation compared with patients without constipation. ${ }^{16}$

The primary objective of this study was to examine the impact on MRU and costs to payers of side effects in patients taking oxycodone $\mathrm{CR}$ alone or in combination with other pain medications for noncancer pain (including those with neuropathic pain symptoms). Other objectives included characterizing this population with respect to their primary pain 
condition, pain relief, side-effect frequency, satisfaction with oxycodone $\mathrm{CR}$, and adherence.

\section{Methods}

\section{Study Design}

An Internet-based survey study of patients currently taking oxycodone CR for chronic noncancer pain was conducted. A convenience sample of adults in the United States participating in a nationally representative research panel (managed by an independent online panel and survey technology provider) was recruited by e-mail invitation between November 2, 2010, and December 13, 2010.

Respondents who reported current use of oxycodone $\mathrm{CR}$ alone or in combination with oxycodone IR or other IR opioids for a primary pain condition that was present for at least the previous 3 months were eligible to participate in the study. Additional criteria were included to exclude patients in severe pain that would likely incur greater MRU and skew the overall results. Specifically, respondents were excluded if they reported currently taking any other extended-release or long-acting opioid prescription medication or if they reported currently taking oxycodone CR for cancer pain. It is unusual for patients to use two long-acting opioids together, and, if so, they are likely to have severe pain, including cancer-related pain. Similarly, respondents were excluded if they reported cancer that was not skin cancer in the previous year because these patients are likely in severe pain and have a different MRU pattern. Respondents also were excluded if they reported kidney or liver problems, since opioids may not be appropriate in these populations. Respondents who reported dental pain, headaches, or migraines were excluded because dental pain is unlikely to be managed using a long-acting opioid, and headache and migraine pain require different treatment strategies than chronic pain. Lastly, respondents who reported receiving workers' compensation related to their current pain were excluded because these patients may be motivated to stay on worker's compensation and, thus, may incur greater MRU.

Respondents had to complete the entire questionnaire to be included in the study. All responses were captured electronically. Respondents were compensated using a points-based incentive program managed by the online panel and survey technology provider valued between $\$ 1$ and $\$ 5$. This study was not subject to Institutional Review Board review.

\section{Survey}

The survey consisted of 100 questions on demographics, clinical characteristics, experience with pain medication (i.e., daily dose, side effects, satisfaction, and adherence), and MRU. Prior to launch, the authors tested the survey to assess functionality, skip patterns, and response ranges. Additionally, the survey was administered to three individuals to assess clarity and understanding of the questions. Survey responses were evaluated again 24 hours after launch. Respondents were not allowed to go back and change answers on previous screens. Each screen contained 1 question with the exception of included validated questionnaires that were displayed to resemble the paperbased format. Measures also were taken to prevent respondents from completing the survey more than 1 time. For example, upon initiation of the survey, the respondents' e-mail addresses had to be both valid and unique (including similar variations) and not be contained on a managed "black list." Additionally, unique combinations of date of birth, name, physical mailing address, and password were all confirmed.

Pain Medication Experience. Respondents were asked how long they had been on oxycodone CR and combination use with short-acting opioids and other medications, such as antidepressants, antiepileptics/anticonvulsants, and pregabalin/ gabapentin. Additionally, they were asked about whether they experienced any of 14 side effects and the level of bother of each side effect on a 5-point scale of "Not at all bothered," "A little bit bothered," "Moderately bothered," "Quite a bit bothered," and "Extremely bothered." Level of satisfaction with oxycodone $\mathrm{CR}$ overall and with relieving pain also was reported on a 5-point scale of "Very dissatisfied," "Somewhat dissatisfied," "Neither satisfied nor dissatisfied," "Somewhat satisfied," and "Very satisfied." Lastly, respondents reported on whether they took oxycodone CR less than instructed by their physicians and, if so, the reasons for taking less than instructed.

Medical Resource Use. MRU that the respondents attributed to side effects from oxycodone CR were collected. Hospitalizations, emergency room (ER) visits, physician visits, and physician calls were collected based on respondents reported use in the previous month. Specifically, respondents were asked to report the number of times they had been admitted to the hospital, visited the ER, and visited and called their physicians to address side effects from taking oxycodone CR in the previous month. If the respondents reported use of any of these medical services, they were asked to indicate the primary reason for use among the following choices: "Inadequate or no pain relief from my oxycodone CR medication," "Side effects from my oxycodone CR medication," or "Other."

Concomitant prescription side-effect medications and chiropractic and physical therapy visits were collected based on respondents' reported current use. Respondents were asked what prescription medications they were currently taking to manage the side effects as a result of taking their oxycodone $\mathrm{CR}$ medication. Respondents indicated one or more responses among the following: none; antiemetics (medications to prevent nausea and vomiting, such as Compazine, Kytril, Zofran, and Anzemet); laxatives (medications to treat constipation, such as Miralax, Glycolax, Cephulac, Chronulac, and Constulose); medication that stimulates saliva production (such as Salagen); and medication to help treat fatigue or daytime sleepiness (such as Ritalin and Adderal). 


\section{Analysis}

Descriptive statistics were calculated to summarize the responses to the survey. Among respondents who reported being bothered by side effects, differences in MRU and costs were examined across levels of side-effect bother to examine the impact of the severity of side-effect bother on MRU and costs. Differences across the levels of side-effect bother were evaluated using logistic regression on the MRU endpoints and linear regression on the costs after a log transformation. Demographic and clinical characteristics across the levels of side-effect bother were examined to control for any differences in the regression models. Statistical significance across the levels of side-effect bother was evaluated at the 0.05 level.

A subgroup analysis of respondents with a neuropathic pain component, which tends to be more severe and leads to greater MRU and costs, also was conducted to examine their levels of side-effect bother, since this population was more likely to be using other opioids and for a longer term, increasing their risk of experiencing more severe opioid-related side effects. This subgroup was composed of respondents who reported low back pain (LBP) with radiating pain, neuropathic pain, or fibromyalgia as their primary pain condition.

Pain Medication Experience. The 5 side-effect bother levels of "Not at all bothered," "A little bit bothered," "Moderately bothered," "Quite a bit bothered," and "Extremely bothered" were collapsed into 4 levels for analysis; specifically, the 4 levels used for analysis were "Not bothered," "A little bit bothered," "Bothered" (included "Moderately bothered" and "Quite a bit bothered"), and "Extremely bothered." Respondents were categorized into one of these 4 side-effect bother levels if they indicated that level of bother for any one of the individual side effects they reported experiencing. Respondents who reported not experiencing any side effects were included in the "Not bothered" level. Lastly, overall satisfaction with oxycodone $\mathrm{CR}$ and satisfaction with oxycodone $\mathrm{CR}$ relieving pain were derived from a composite of the responses of "Somewhat satisfied" and "Very satisfied" among possible responses that also included "Neither satisfied nor dissatisfied," "Somewhat dissatisfied," and "Very dissatisfied."

Medical Resource Use and Payer Costs. Among respondents who reported being bothered by one or more side effects, the number and percentage of respondents hospitalized, visiting the ER, visiting their physicians, and calling their physicians were calculated. The mean number of hospitalizations and visits was calculated among those reporting use. Additionally, the number and percentage of respondents reporting concomitant side-effect medications and chiropractic and physical therapy visits were calculated.

Costs to the payer were based on the MRU associated with side effects reported by the respondents. The cost for a hospitalization was based on the 2010 Medicare Provider Analysis and Review (MedPAR) file for Medicare Severity DiagnosisRelated Groups (MS-DRGs) associated with primary diagnoses of gastrointestinal (GI) side effects, specifically nausea/vomiting, constipation, and bowel obstruction. Based on primary diagnoses identified with International Classification of Diseases, Ninth Revision, Clinical Modification (ICD-9-CM) diagnoses codes of 787.01-787.04 for nausea/vomiting, ICD-9-CM diagnoses codes of 564.00-564.02 and 564.09 for constipation, and ICD-9-CM diagnoses codes of 560.1 and 560.39 for bowel obstruction, the frequency weighted average cost of the most common MS-DRGs (over 95\% of claims with these diagnoses) was calculated. The associated MS-DRGs were $388(\$ 8,271$; $7.4 \%$ of claims), $389(\$ 4,923 ; 18.7 \%$ of claims), and 390 ( $\$ 2,765 ; 8.2 \%$ of claims) for GI obstruction diagnoses and 391 ( $\$ 5,902 ; 4.8 \%$ of claims) for nausea/vomiting and $392(\$ 3,439$; $61.0 \%$ of claims) for constipation diagnoses, for a frequency weighted average cost of $\$ 4,136$ per hospitalization. Payer costs for hospitalizations in the previous month were calculated by multiplying the weighted average cost per hospitalization by the number of hospitalizations reported by the respondent for the previous month.

Payer costs for ER visits, physician office visits, and physical and chiropractic therapy were based on 2010 national Medicare reimbursement rates. ${ }^{17}$ Payer costs for ER visits were calculated based on the sum of the national Medicare reimbursement rates of $\$ 140.18$ for Ambulatory Payment Classification (APC) code 614 (level 3 type A emergency visits) and $\$ 61.70$ for Current Procedure Terminology (CPT) code 99283 (emergency department visit for the evaluation and management of a patient-moderate complexity) and multiplied by the number of ER visits reported by the respondent for the previous month. Payer costs for physician office visits were based on the national Medicare reimbursement rate of $\$ 65.67$ for CPT 99213 (evaluation and management of an established patient) and multiplied by the number of office visits reported by the respondent for the previous month.

Payer costs for side-effect medications were calculated based on average wholesale price (AWP) minus 20\% ${ }^{18,19}$ Unit costs per pill were calculated using the 2010 lowest manufacturer's listed AWP per pill, minus 20\%. Payer costs for side-effect medications were calculated by multiplying the unit cost per pill by the number of pills taken in the previous month. A frequency of use of 12 days in the previous month (roughly 3 times per week) was used. Additionally, the lowest recommended daily dose obtained from the medication's prescribing information was used for each medication reported by the respondents. It should be noted that respondents did not report specific prescription side-effect medications but did report the class of prescription side-effect medications used. For respondents reporting use of antiemetics, an average cost of prochlorperazine maleate and ondansetron hydrochloride was assumed because both were considered commonly prescribed 
according to two physicians who practice pain management. For laxatives, lactulose was used; for fatigue, methylphenidate hydrochloride was used; and for stimulating saliva production, pilocarpine hydrochloride was used.

Lastly, payer costs for physical and chiropractic therapy were based on the national Medicare reimbursement rate of $\$ 36.70$ for CPT 97140 (manual therapy techniques [e.g., mobilization/ manipulation, manual lymphatic drainage, manual traction], 1 or more regions, each 15 minutes). Costs for the previous month were calculated assuming 1 visit for those respondents who reported physical or chiropractic therapy in the previous month for management of side effects.

\section{Results}

Among the 58,058 adults who responded to an e-mail invitation to participate in a survey on pain, 52,632 (90.7\%) agreed to participate by answering all eligibility questions. Among the $52,632,15,322$ were taking a prescription pain medication (976 oxycodone CR with no other extended-release or longacting opioid), of which 558 met the additional inclusion and exclusion criteria and 432 completed the survey, for a completion rate of $77.4 \%$ (Figure 1).

\section{Demographics and Clinical Characteristics}

The average age across the 432 respondents was 41.8 years (14.89; Table 1). The majority (88.4\%) was Caucasian, and $63.7 \%$ were female. Half were employed full time (38.2\%) or part time (11.8\%). Pain impacted $23.1 \%$ of respondents' employment status $(6.0 \%$ employed part time because of pain and $17.1 \%$ unemployed because of pain). Private health insurance was reported by $60.6 \%$ of respondents and private prescription drug insurance was reported by $61.6 \%$ of respondents.

Respondents reported having their primary pain condition for an average of 5.4 (7.42) years (Table 1). LBP was reported by $41.2 \%$ of respondents as their primary pain condition for using oxycodone CR. Osteoarthritis/rheumatoid arthritis/degenerative joint disease/joint pain was the second most reported pain condition (20.4\%) followed by neuropathic pain (10.6\%) and fibromyalgia (9.0\%). Among those with LBP, $75.3 \%$ reported having radiating pain either into the upper leg only or into the lower leg below the knee. Additionally, $82.6 \%$ of respondents reported having one or more of the following coexisting medical conditions: depression (38.9\%), sleep disturbances (32.2\%), high blood pressure $(28.0 \%)$, anxiety disorders (27.1\%), high cholesterol (24.8\%), migraine/chronic headache (23.6\%), asthma/chronic obstructive pulmonary disease/lung disease (17.4\%), and diabetes (12.7\%), among others less frequently reported.

\section{Pain Medication Experience}

The reported average length of time on oxycodone $C R$ was 2.1 (3.23) years (Table 2). Less than half (43.3\%) of respon-

\section{FIGURE 1 Study Sample Selection Flowchart}

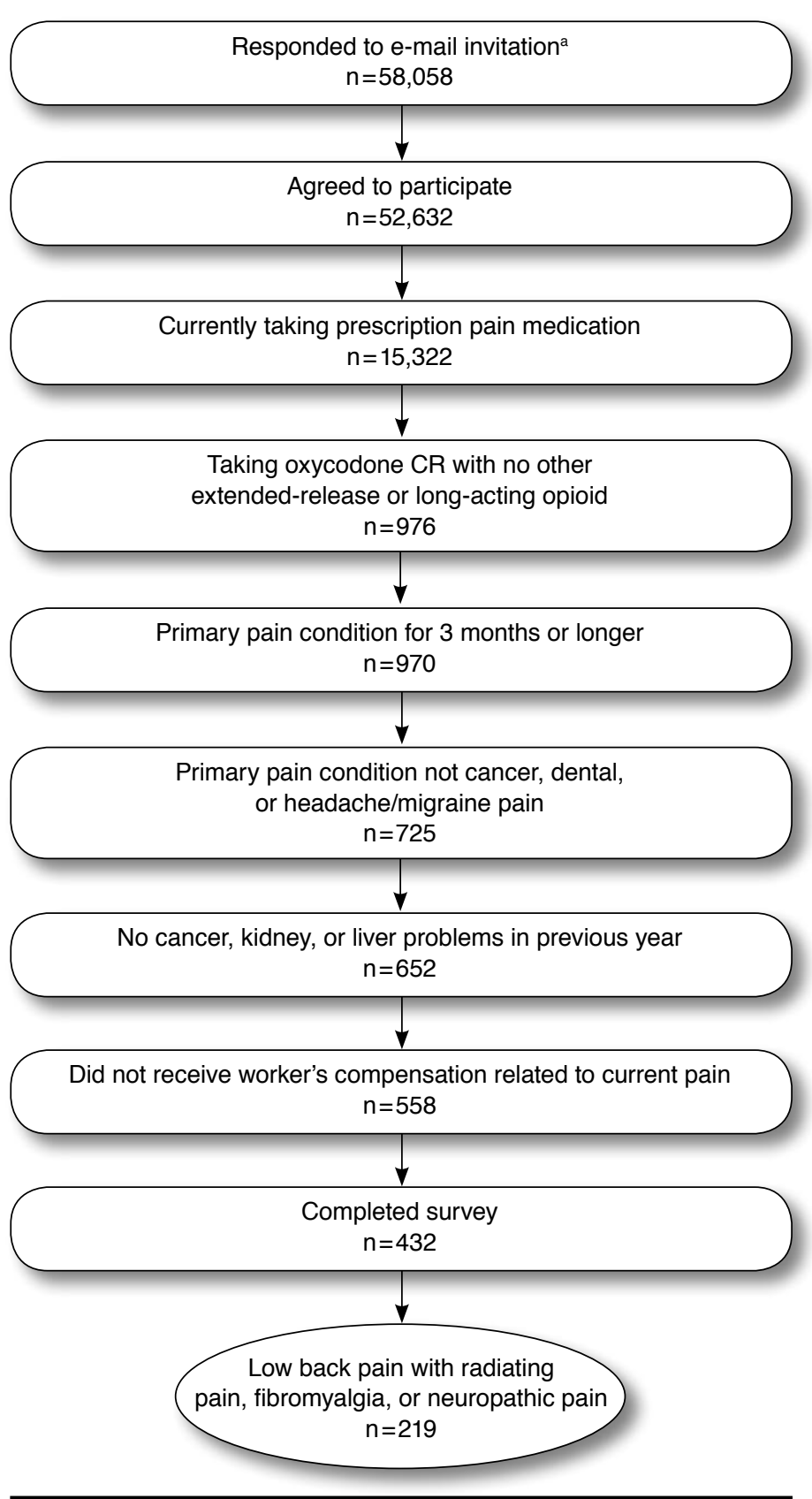

aAn e-mail invitation to participate in a survey on pain was sent to adults participating in a research panel managed by an online panel and survey technology provider.

$C R=$ controlled-release . 


\section{TABLE 1 Demographic and Clinical Characteristics}

\begin{tabular}{|c|c|c|c|c|}
\hline \multirow[b]{2}{*}{ Age, mean (SD) } & \multicolumn{2}{|c|}{$\begin{array}{l}\text { Study Sample } \\
\quad(\mathrm{N}=432)\end{array}$} & \multicolumn{2}{|c|}{$\begin{array}{l}\text { Neuropathic Pain Subgroup } \\
\qquad(\mathrm{n}=219)\end{array}$} \\
\hline & 41.8 & $(14.89)$ & 39.6 & $(13.26)$ \\
\hline Female, n (\%) & 275 & $(63.7)$ & 139 & $(63.5)$ \\
\hline \multicolumn{5}{|l|}{ Race, $\mathrm{n}(\%)$} \\
\hline Caucasian & 382 & $(88.4)$ & 194 & $(88.6)$ \\
\hline Black or African American & 37 & $(8.6)$ & 19 & $(8.7)$ \\
\hline Other & 13 & $(3.0)$ & 6 & $(2.7)$ \\
\hline \multicolumn{5}{|l|}{ Employment status, n (\%) } \\
\hline Employed full time (30 hours or more per week) & 165 & $(38.2)$ & 91 & $(41.6)$ \\
\hline Full-time homemaker & 58 & $(13.4)$ & 28 & $(12.8)$ \\
\hline Employed part time because of pain ( $<30$ hours per week) & 26 & $(6.0)$ & 11 & $(5.0)$ \\
\hline Employed part time not because of pain ( $<30$ hours per week) & 25 & $(5.8)$ & 13 & $(5.9)$ \\
\hline Unemployed because of pain & 74 & $(17.1)$ & 49 & $(22.4)$ \\
\hline Unemployed for reason other than pain & 34 & $(7.9)$ & 12 & $(5.5)$ \\
\hline Retired & 49 & $(11.3)$ & 15 & $(6.8)$ \\
\hline Volunteer & 1 & $(0.2)$ & 0 & $(0.0)$ \\
\hline Years with pain condition, mean (SD) & 5.4 & $(7.42)$ & 4.6 & $(5.98)$ \\
\hline \multicolumn{5}{|l|}{ Pain condition, n (\%) } \\
\hline Low back pain (LBP) & 178 & $(41.2)$ & 134 & $(61.2)$ \\
\hline Osteoarthritis/rheumatoid arthritis/degenerative joint disease/joint pain & 88 & $(20.4)$ & 0 & $(0.0)$ \\
\hline Neuropathic pain & 46 & $(10.6)$ & 46 & $(21.0)$ \\
\hline Fibromyalgia & 39 & $(9.0)$ & 39 & $(17.8)$ \\
\hline Neck pain & 29 & $(6.7)$ & 0 & $(0.0)$ \\
\hline Recent surgery & 17 & $(3.9)$ & 0 & $(0.0)$ \\
\hline Other & 35 & $(8.1)$ & 0 & $(0.0)$ \\
\hline \multicolumn{5}{|l|}{ Location of radiating pain among LBP, $\mathrm{n}(\%)$} \\
\hline Radiates into upper leg only & 57 & $(32.0)$ & 57 & $(42.5)$ \\
\hline Radiates into lower leg below the knee & 77 & $(43.3)$ & 77 & $(57.5)$ \\
\hline Neither & 44 & $(24.7)$ & 0 & $(0.0)$ \\
\hline \multicolumn{5}{|l|}{ Coexisting medical conditions } \\
\hline No other medical problems, $\mathrm{n}(\%)$ & 75 & $(17.4)$ & 42 & $(19.2)$ \\
\hline Depression, $\mathrm{n}(\%)$ & 168 & $(38.9)$ & 96 & $(43.8)$ \\
\hline Sleep disturbances, $\mathrm{n}(\%)$ & 139 & $(32.2)$ & 75 & $(34.2)$ \\
\hline High blood pressure, n (\%) & 121 & $(28.0)$ & 53 & $(24.2)$ \\
\hline Anxiety disorders, $\mathrm{n}(\%)$ & 117 & $(27.1)$ & 63 & $(28.8)$ \\
\hline High cholesterol, n (\%) & 107 & $(24.8)$ & 55 & $(25.1)$ \\
\hline Migraine/chronic headache, $\mathrm{n}(\%)$ & 102 & $(23.6)$ & 57 & $(26.0)$ \\
\hline Asthma/COPD/lung disease, $\mathrm{n}(\%)$ & 75 & $(17.4)$ & 32 & $(14.6)$ \\
\hline Diabetes, n (\%) & 55 & $(12.7)$ & 34 & $(15.5)$ \\
\hline Thyroid disease, $\mathrm{n}(\%)$ & 34 & $(7.9)$ & 16 & $(7.3)$ \\
\hline Heart disease, $\mathrm{n}(\%)$ & 28 & $(6.5)$ & 15 & $(6.8)$ \\
\hline Bleeding or clotting disorder, $\mathrm{n}(\%)$ & 14 & $(3.2)$ & 5 & $(2.3)$ \\
\hline Stroke, n (\%) & 6 & $(1.4)$ & 3 & $(1.4)$ \\
\hline HIV/AIDS, n (\%) & 5 & $(1.2)$ & 4 & $(1.8)$ \\
\hline Multiple sclerosis, n (\%) & 5 & $(1.2)$ & 1 & $(0.5)$ \\
\hline Other, n (\%) & 50 & $(11.6)$ & 20 & $(9.1)$ \\
\hline \multicolumn{5}{|l|}{ Health insurance, $\mathrm{n}(\%)$} \\
\hline Private & 262 & $(60.6)$ & 146 & $(66.7)$ \\
\hline Medicaid & 51 & $(11.8)$ & 25 & (11.4) \\
\hline Medicare & 34 & $(7.9)$ & 11 & $(5.0)$ \\
\hline Veterans Affairs/TRICARE & 28 & $(6.5)$ & 15 & $(6.8)$ \\
\hline Other & 14 & $(3.2)$ & 4 & $(1.8)$ \\
\hline None & 43 & $(10.0)$ & 18 & $(8.2)$ \\
\hline \multicolumn{5}{|l|}{ Prescription drug insurance, $\mathrm{n}(\%)$} \\
\hline Private & 266 & $(61.6)$ & 148 & $(67.6)$ \\
\hline
\end{tabular}




\section{TABLE 1 Demographic and Clinical Characteristics (continued)}

\begin{tabular}{|c|c|c|c|c|}
\hline & \multicolumn{2}{|c|}{$\begin{array}{l}\text { Study Sample } \\
\quad(\mathrm{N}=432)\end{array}$} & \multicolumn{2}{|c|}{$\begin{array}{l}\text { Neuropathic Pain Subgroup } \\
\qquad(\mathrm{n}=219)\end{array}$} \\
\hline \multicolumn{5}{|c|}{ Prescription drug insurance, $\mathrm{n}(\%)$} \\
\hline Medicaid & 51 & $(11.8)$ & 25 & $(11.4)$ \\
\hline Medicare & 25 & $(5.8)$ & 8 & $(3.7)$ \\
\hline Veterans Affairs/TRICARE & 32 & $(7.4)$ & 18 & $(8.2)$ \\
\hline Other & 13 & $(3.0)$ & 1 & $(0.5)$ \\
\hline None & 45 & $(10.4)$ & 19 & $(8.7)$ \\
\hline
\end{tabular}

\section{TABLE 2 Oxycodone Medication Use, Satisfaction, and Adherence}

\begin{tabular}{|c|c|c|c|c|}
\hline \multirow[b]{2}{*}{ Years on oxycodone CR, mean (SD) } & \multicolumn{2}{|c|}{$\begin{array}{l}\text { Study Sample } \\
\qquad(\mathrm{N}=432)\end{array}$} & \multicolumn{2}{|c|}{$\begin{array}{l}\text { Neuropathic Pain Subgroup } \\
\qquad(\mathrm{n}=219)\end{array}$} \\
\hline & 2.1 & $(3.23)$ & 1.9 & $(2.47)$ \\
\hline \multicolumn{5}{|l|}{ Oxycodone CR medication use } \\
\hline Monotherapy (not with oxycodone IR or other SAOs), n (\%) & 187 & $(43.3)$ & 89 & $(40.6)$ \\
\hline Combined with oxycodone IR (no other SAOs), n (\%) & 57 & $(13.2)$ & 24 & $(11.0)$ \\
\hline Combined with other SAOs (no oxycodone IR), n (\%) & 120 & $(27.8)$ & 71 & $(32.4)$ \\
\hline Combined with oxycodone IR and other SAOs, n (\%) & 68 & $(15.7)$ & 35 & $(16.0)$ \\
\hline Combined with antidepressants, n (\%) & 70 & $(16.2)$ & 38 & $(17.4)$ \\
\hline Combined with antiepileptics/anticonvulsants, $\mathrm{n}(\%)$ & 38 & $(8.8)$ & 25 & $(11.4)$ \\
\hline Combined with pregabalin/gabapentin, n (\%) & 37 & $(8.6)$ & 24 & $(11.0)$ \\
\hline \multicolumn{5}{|l|}{ Satisfied with oxycodone CR } \\
\hline Overall, n (\%) & 325 & $(75.2)$ & 171 & $(78.1)$ \\
\hline Relieving pain, $\mathrm{n}(\%)$ & 353 & $(81.7)$ & 182 & $(83.1)$ \\
\hline Take oxycodone CR less than instructed, n (\%) & 237 & (54.9) & 109 & $(49.8)$ \\
\hline \multicolumn{5}{|l|}{ Reasons for taking less than instructed } \\
\hline Do not take when not feeling pain, $\mathrm{n}(\%)$ & 157 & $(66.2)$ & 69 & $(63.3)$ \\
\hline Fear of developing dependence or becoming addicted, $\mathrm{n}(\%)$ & 145 & $(61.2)$ & 69 & $(63.3)$ \\
\hline Side effects are bothersome, $\mathrm{n}(\%)$ & 97 & $(40.9)$ & 39 & $(35.8)$ \\
\hline Provides little or no pain relief, n (\%) & 54 & $(22.8)$ & 22 & $(20.2)$ \\
\hline Forget to take it, n (\%) & 52 & $(21.9)$ & 23 & $(21.1)$ \\
\hline Inconvenient, n (\%) & 43 & $(18.1)$ & 24 & $(22.0)$ \\
\hline Other, n (\%) & 19 & $(8.0)$ & 6 & $(5.5)$ \\
\hline
\end{tabular}

oxycodone IR. More than a one-fourth (27.8\%) reported taking oxycodone CR combined with other SAOs. A number of respondents also reported taking oxycodone CR combined with other medications used for pain, including antidepressants (16.2\%), antiepileptics/anticonvulsants (8.8\%), and pregabalin/gabapentin (8.6\%).

Three-fourths (75.2\%) of respondents reported being satisfied overall with oxycodone CR, and $81.7 \%$ of respondents reported being satisfied with it relieving paid (Table 2). More than half (54.9\%) reported taking oxycodone CR less than instructed. The primary reasons reported for taking less than instructed included the following: do not take when not feeling pain (66.2\%), fear of developing dependence or becoming addicted (61.2\%), side effects are bothersome (40.9\%), provides little or no pain relief (22.8\%), forget to take it (21.9\%), and inconvenient (18.1\%).

Overall, $82.4 \%$ of respondents reported experiencing at least 1 side effect, and $77.5 \%$ reported being bothered by side effects: 18.8\% "A little bothered"; $41.0 \%$ "Bothered"; 17.8\% "Extremely bothered" (Figure 2). The most frequently reported side effects (>25\%) were drowsiness (41.4\%), constipation (37.0\%), fatigue or daytime sleepiness (36.6\%), and dizziness (27.1\%). Over half $(54.6 \%)$ of the respondents reported being bothered by dizziness, headache, or drowsiness, and $44.4 \%$ reported being bothered by nausea, vomiting, or constipation. 


\section{FIGURE 2 Percentage of Respondents Reporting Side Effects and Level of Bother}

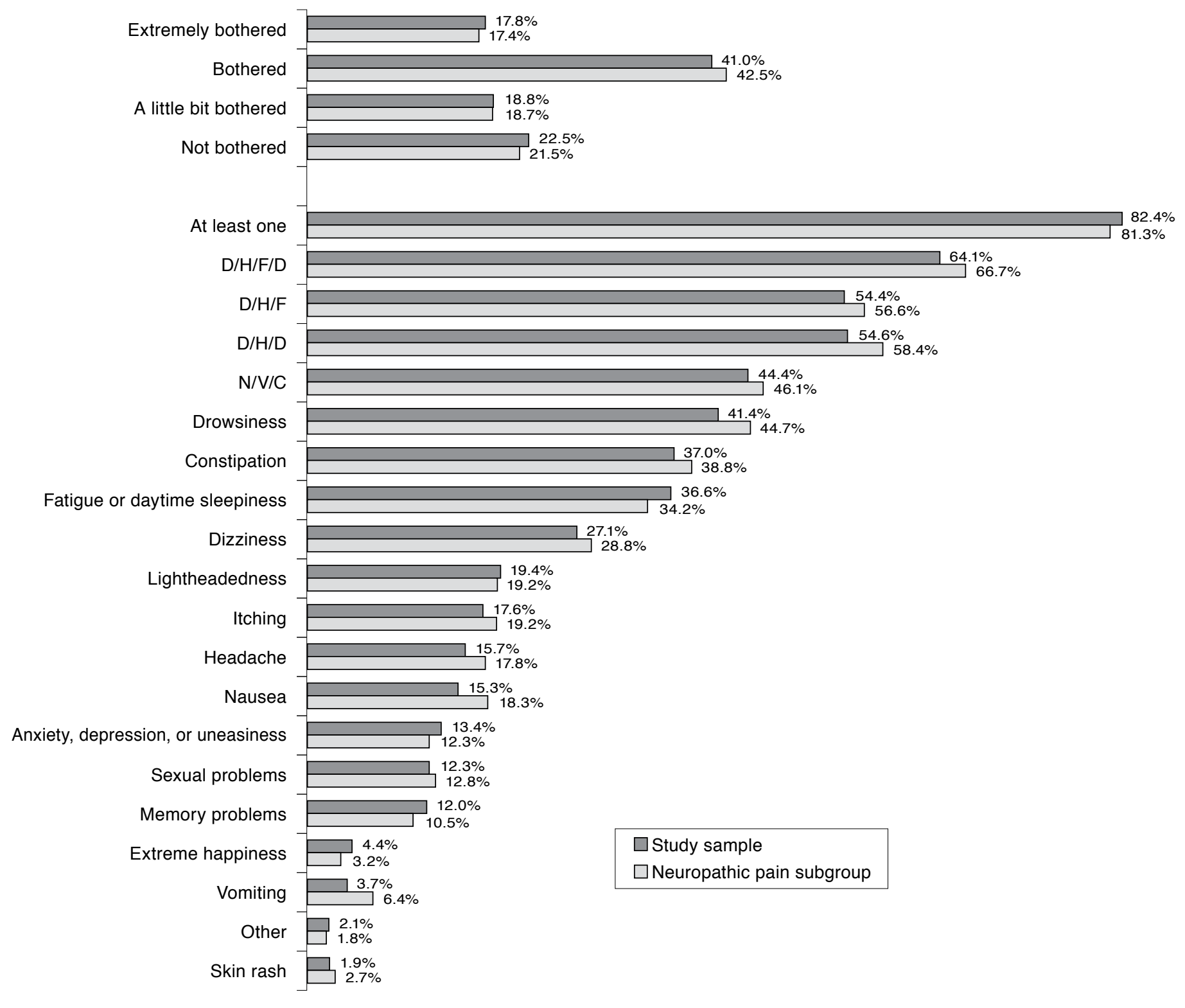

D/H/D = Dizziness/Headache/Drowsiness composite; D/H/F=Dizziness/Headache/Fatigue or daytime sleepiness composite; D/H/F/D =Dizziness/Headache/Fatigue or daytime sleepiness/drowsiness composite; N/V/C = Nausea/Vomiting/Constipation composite.

\section{Medical Resource Use}

Among respondents who reported being bothered by one or more side effects in the previous month, MRU associated with side effects was reported by $39.1 \%$ of respondents (Table 3). This percentage significantly increased as the level of side-effect bother increased from 19.8\% "A little bit bothered" to 38.4\% "Bothered" to 61.0\% "Extremely bothered" ( $P<0.001$, adjusted for depression, heart failure, and location of radiating pain).
Over the previous month, $3.9 \%$ of the respondents reported being hospitalized an average of $1.3(0.48)$ times; $3.0 \%$ reported visiting the ER an average of $1.4(0.52)$ times; $15.5 \%$ reported visiting their physician offices an average of 1.6 (1.03) times; and $13.7 \%$ reported calling their physicians an average of 1.8 (1.40) times (Table 3). The percentage of respondents who reported visiting their physicians significantly increased as the level of side-effect bother increased from $4.9 \%$ "A little bit 
Economic Study on the Impact of Side Effects in Patients Taking Oxycodone Controlled-Release for Noncancer Pain

TABLE 3 Medical Resource Use in Previous Month Associated with Side Effects

\begin{tabular}{|c|c|c|c|c|c|c|c|c|c|c|}
\hline & \multicolumn{5}{|c|}{ Study Sample } & \multicolumn{5}{|c|}{ Neuropathic Pain Subgroup } \\
\hline & $\begin{array}{l}\text { Bothered } \\
(\mathrm{N}=335)\end{array}$ & $\begin{array}{c}\text { A Little } \\
\text { Bothered } \\
(\mathrm{n}=81)\end{array}$ & $\begin{array}{c}\text { Moderately } \\
\text { Bothered } \\
(\mathrm{n}=177)\end{array}$ & $\begin{array}{c}\text { Extremely } \\
\text { Bothered } \\
(\mathrm{n}=77)\end{array}$ & $\begin{array}{c}P \\
\text { Value }^{\mathrm{a}}\end{array}$ & $\begin{array}{c}\text { Bothered } \\
(\mathrm{n}=172)\end{array}$ & $\begin{array}{c}\text { A Little } \\
\text { Bothered } \\
(\mathrm{n}=41)\end{array}$ & $\begin{array}{c}\text { Moderately } \\
\text { Bothered } \\
(\mathbf{n}=93)\end{array}$ & $\begin{array}{c}\text { Extremely } \\
\text { Bothered } \\
(\mathrm{n}=38)\end{array}$ & $P$ Value $^{\mathrm{b}}$ \\
\hline $\begin{array}{l}\text { Any medical resource } \\
\text { use, } \mathrm{n}(\%)\end{array}$ & $131 \quad(39.1)$ & $16 \quad(19.8)$ & 68 (38.4) & $47(61.0)$ & $<0.001$ & $66(38.4)$ & $7(17.1)$ & $35(37.6)$ & $24(63.2)$ & $<0.001$ \\
\hline Hospitalizations, n (\%) & $13 \quad(3.9)$ & $1 \quad(1.2)$ & $7 \quad(4.0)$ & $5 \quad(6.5)$ & 0.143 & $8 \quad(4.7)$ & $1 \quad(2.4)$ & $4 \quad(4.3)$ & $3(7.9)$ & 0.311 \\
\hline Mean $(S D)^{c}$ & $1.3(0.48)$ & $1.00 \quad \mathrm{NA}$ & $1.3(0.49)$ & $1.4(0.55)$ & & $1.3(0.46)$ & $1.0 \quad \mathrm{NA}$ & $1.3(0.50)$ & $1.3(0.58)$ & \\
\hline ER visits, n (\%) & $10 \quad(3.0)$ & $1 \quad(1.2)$ & $5 \quad(2.8)$ & $4 \quad(5.2)$ & 0.320 & $6 \quad(3.5)$ & $1 \quad(2.4)$ & $3 \quad(3.2)$ & $2(5.3)$ & 0.504 \\
\hline Mean $(S D)^{c}$ & $1.4(0.52)$ & $2.0 \quad \mathrm{NA}$ & $1.4(0.55)$ & $1.3(0.50)$ & & $1.5(0.55)$ & $2.0 \quad \mathrm{NA}$ & $1.3(0.58)$ & $1.5(0.71)$ & \\
\hline Physician visits, $\mathrm{n}(\%)^{\mathrm{d}}$ & $52(15.5)$ & $\begin{array}{ll}4 & (4.9) \\
\end{array}$ & $28(15.8)$ & $20(26.0)$ & 0.002 & $29(16.9)$ & $2 \quad(4.9)$ & $15(16.1)$ & $12(31.6)$ & 0.006 \\
\hline Mean $(S D) c$ & $1.6(1.03)$ & $1.0(0.00)$ & $1.6 \quad(1.10)$ & $1.8(1.02)$ & & $1.6(1.12)$ & $1.0(0.00)$ & $1.8(1.42)$ & $1.5(0.67)$ & \\
\hline Physician calls, n (\%) & $46(13.7)$ & $4 \quad(4.9)$ & $25(14.1)$ & $17(22.1)$ & 0.003 & $25(14.5)$ & $3(7.3)$ & $15(16.1)$ & $7(18.4)$ & 0.223 \\
\hline Mean $(S D)^{c}$ & $1.8(1.40)$ & $1.5(1.00)$ & $1.5(0.82)$ & $2.4(1.94)$ & & $1.5(0.87)$ & $1.7(1.15)$ & $1.5(0.92)$ & $1.39(0.76)$ & \\
\hline $\begin{array}{l}\text { Prescription side-effect } \\
\text { medications, } \mathrm{n}(\%)\end{array}$ & 73 (21.8) & $9(11.1)$ & $34(19.2)$ & $30(39.0)$ & $<0.001$ & $33(19.2)$ & $2 \quad(4.9)$ & $18(19.4)$ & $13(34.2)$ & 0.004 \\
\hline Alternative therapy, n (\%) & $8 \quad(2.4)$ & $1 \quad(1.2)$ & $4 \quad(2.3)$ & $3 \quad(3.9)$ & 0.219 & $2 \quad(1.2)$ & $1 \quad(2.4)$ & $1 \quad(1.1)$ & $\begin{array}{ll}0 & (0.0) \\
\end{array}$ & 0.494 \\
\hline $\begin{array}{l}{ }^{a} \text { Chi-square test from logist } \\
{ }^{b} \text { Chi-square test from logist } \\
{ }^{c} \text { Among respondents with s } \\
{ }^{d} \text { Routine follow-up visits ex }\end{array}$ & $\begin{array}{l}\text { ion; adjl } \\
\text { ion; adjl } \\
\text { nedical } r\end{array}$ & $\begin{array}{l}\text { for depre } \\
\text { for gende } \\
\text { ce. }\end{array}$ & hear & and $l$ & & & & & & \\
\hline
\end{tabular}

bothered" to $15.8 \%$ "Bothered" to $26.0 \%$ "Extremely bothered" ( $P=0.002$, adjusted for depression, heart failure, and location of radiating pain). Similarly, the percentage of respondents who reported calling their physicians significantly increased as the level of side-effect bother increased from $4.9 \%$ "A little bit bothered" to $14.1 \%$ "Bothered" to 22.1\% "Extremely bothered" $(P=0.003$, adjusted for depression, heart failure, and location of radiating pain). The percentage of respondents reporting hospitalizations and ER visits increased as the level of side-effect bother increased; however, the increases were not statistically significant $(P=0.143$ and $P=0.320$, respectively, adjusted for depression, heart failure, and location of radiating pain).

Concomitant prescription side-effect medication use was reported by $21.8 \%$ of respondents, and physical and chiropractic therapy visits were reported by $2.4 \%$ of respondents (Table 3). Overall, the percentage of respondents who reported use of concomitant prescription side-effect medications significantly increased as the level of side-effect bother increased from $11.1 \%$ "A little bit bothered" to $19.2 \%$ "Bothered" to 39.0\% "Extremely bothered" $(P<0.001$, adjusted for depression, heart failure, and location of radiating pain). The percentage of respondents who reported physical and chiropractic therapy visits did not increase as the level of side-effect bother increased ( $P=0.219$, adjusted for depression, heart failure, and location of radiating pain).

\section{Payer Costs}

Total average payer costs per respondent in the previous month associated with side effects were $\$ 238$ (\$1,159; Table 4). These costs significantly increased as the level of side-effect bother increased from \$61 (\$512) among those "A little bit bothered" to $\$ 238(\$ 1,160)$ among those "Bothered" to $\$ 425(\$ 1,561)$ among those "Extremely bothered" ( $P<0.001$, adjusted for depression, heart failure, and location of radiating pain). Total average payer costs were driven by hospitalizations of $\$ 210(\$ 1,112)$ per respondent in the previous month, which increased as the level of side-effect bother increased; however, the increase was not significant $(P=0.136$, adjusted for depression, heart failure, and location of radiating pain). Average payer costs for ER visits per respondent in the previous month were $\$ 8(\$ 51)$ and also did not significantly increase as the level of side-effect bother increased ( $P=0.342$, adjusted for depression, heart failure, and location of radiating pain).

Average payer costs per respondent in the previous month for physician visits were $\$ 16(\$ 46)$ and were almost double among those "Extremely bothered" at $\$ 30$ (\$61) compared with those "Bothered" at \$16 (\$47) and those "A little bit bothered" at $\$ 3$ ( $\$ 14 ; P=0.001$, adjusted for depression, heart failure, and location of radiating pain; Table 4). Average payer costs per respondent in the previous month for concomitant prescription side-effect medications were $\$ 2(\$ 7)$ and significantly increased as the level of side-effect bother increased from $\$ 1$ (\$4) among those "A little bit bothered" to \$2 (\$6) among those "Bothered" to \$4 (\$10) among those "Extremely bothered" $(P=0.001$, adjusted for depression, heart failure, and location of radiating pain). Lastly, average payer costs per respondent in the previous month for physical and chiropractic therapy visits were \$1 
TABLE 4 Payer Costs in Previous Month Associated with Side Effects

\begin{tabular}{|c|c|c|c|c|c|c|c|c|c|c|}
\hline \multirow{3}{*}{$\begin{array}{l}\text { Hospitalizations, mean (SD) } \\
\end{array}$} & \multicolumn{5}{|c|}{ Study Sample } & \multicolumn{5}{|c|}{ Neuropathic Pain Subgroup } \\
\hline & \multirow{2}{*}{\begin{tabular}{|c|}
$\begin{array}{c}\text { Bothered } \\
(\mathrm{N}=335)\end{array}$ \\
$210(1,112)$ \\
\end{tabular}} & $\begin{array}{l}\text { A Little } \\
\text { Bothered } \\
(\mathrm{n}=81)\end{array}$ & \multirow{2}{*}{\begin{tabular}{|c|}
$\begin{array}{c}\text { Moderately } \\
\text { Bothered } \\
(\mathbf{n}=\mathbf{1 7 7})\end{array}$ \\
$210(1,104)$ \\
\end{tabular}} & \multirow{2}{*}{\begin{tabular}{|c|c}
$\begin{array}{c}\text { Extremely } \\
\text { Bothered } \\
(\mathbf{n}=77)\end{array}$ \\
$376(1,527)$ \\
\end{tabular}} & \multirow{2}{*}{$\begin{array}{c}\begin{array}{c}P \\
\text { Value }^{\mathrm{a}}\end{array} \\
0.136 \\
\end{array}$} & \multirow{2}{*}{$\begin{array}{c}\text { Bothered } \\
(\mathrm{N}=172)\end{array}$} & $\begin{array}{c}\text { A Little } \\
\text { Bothered } \\
(n=41)\end{array}$ & \multirow{2}{*}{$\begin{array}{c}\text { Moderately } \\
\text { Bothered } \\
(\mathbf{n}=93)\end{array}$} & \multirow{2}{*}{\begin{tabular}{|c|}
$\begin{array}{c}\text { Extremely } \\
\text { Bothered } \\
(\mathbf{n}=38)\end{array}$ \\
$435(1,606)$ \\
\end{tabular}} & \multirow{2}{*}{$\begin{array}{c}\begin{array}{c}P \\
\text { Value }^{b}\end{array} \\
0.309 \\
\end{array}$} \\
\hline & & $51 \quad(460)$ & & & & & $101 \quad(646)$ & & & \\
\hline ER visits, mean (SD) & $(51)$ & $(45)$ & $(50)$ & $(60)$ & 0.342 & (59) & $(63)$ & $(51)$ & $(72)$ & 0.528 \\
\hline Physician visits, mean (SD)c & $(46)$ & (14) & $(47)$ & $30 \quad(61)$ & 0.001 & $(50)$ & (14) & $(57)$ & $(52)$ & 0.005 \\
\hline $\begin{array}{l}\text { Side-effect medications, } \\
\text { mean (SD) }\end{array}$ & (7) & (4) & (6) & (10) & 0.001 & (7) & (1) & (6) & (11) & 0.002 \\
\hline $\begin{array}{l}\text { Alternative therapies, } \\
\text { mean (SD) }\end{array}$ & (6) & (4) & (6) & (7) & 0.210 & (4) & $1 \quad(5.7)$ & (4) & (0) & 0.548 \\
\hline Total payer costs & & & & & $<0.001$ & & & & & 0.001 \\
\hline Mean (SD) & $238(1,159)$ & $61 \quad(512)$ & $238(1,160)$ & $425(1,561)$ & & $272(1,210)$ & $115 \quad(719)$ & $253(1,188)$ & $488(1,619)$ & \\
\hline Median (range) & $\begin{array}{c}0.0 \\
(0-9,070) \\
\end{array}$ & $\begin{array}{c}0.0 \\
(0-4,605) \\
\end{array}$ & $\begin{array}{c}0.0 \\
(0-9,070) \\
\end{array}$ & $\begin{array}{c}4.0 \\
(0-8,576) \\
\end{array}$ & & $\begin{array}{c}0.0 \\
(0-9,070) \\
\end{array}$ & $\begin{array}{c}0.0 \\
(0-4,605) \\
\end{array}$ & $\begin{array}{c}0.0 \\
(0-9,070) \\
\end{array}$ & $\begin{array}{c}4.0 \\
(0-8,272) \\
\end{array}$ & \\
\hline 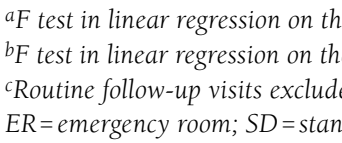 & 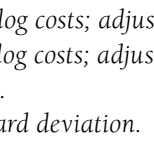 & & & & & & & & & \\
\hline
\end{tabular}

(\$6) and did not significantly increase as the level of side-effect bother increased $(P=0.210$, adjusted for depression, heart failure, and location of radiating pain).

\section{Neuropathic Pain Subgroup}

Half $(50.7 \%)$ of all respondents comprised the neuropathic pain subgroup (Table 1). Almost two-thirds (61.2\%) reported LBP as their primary pain condition, followed by neuropathic pain $(21.0 \%)$ and fibromyalgia (17.8\%).

The reported average length of time on oxycodone $\mathrm{CR}$ was 1.9 (2.47) years (Table 2). Less than half (40.6\%) of respondents reported taking oxycodone $\mathrm{CR}$ without concomitant use of oxycodone IR or other SAOs, and $49.8 \%$ reported taking oxycodone CR less than instructed. Over three-fourths (78.1\%) of respondents reported being satisfied overall with oxycodone CR. Overall, $81.3 \%$ of respondents reported experiencing at least 1 side effect, and $78.5 \%$ reported being bothered by side effects (18.7\% "A little bothered," 42.5\% "Bothered," 17.4\% "Extremely bothered"; Figure 2).

Among neuropathic pain respondents who reported being bothered by one or more side effects in the previous month, MRU associated with side effects was reported by $38.4 \%$ of respondents (Table 3). This percentage significantly increased as the level of side-effect bother increased from 17.1\% "A little bit bothered" to $37.6 \%$ "Bothered" to $63.2 \%$ "Extremely bothered" ( $P<0.001$, adjusted for gender and location of radiating pain). Total average payer costs per respondent in the previous month associated with side effects were $\$ 272$ ( $\$ 1,210$; Table 4). These costs significantly increased as the level of side-effect bother increased from \$115 (\$719) among those "A little bit bothered" to $\$ 253(\$ 1,188)$ among those "Bothered" to $\$ 488(\$ 1,619)$ among those "Extremely bothered" ( $P=0.001$; adjusted for gender and location of radiating pain).

\section{Discussion}

This study sought to characterize the experience of patients taking oxycodone $\mathrm{CR}$, alone or in combination with other pain medications, for noncancer pain and to examine MRU and costs associated with side effects. Half of the respondents reported a neuropathic pain condition (LBP with radiating pain, neuropathic pain, or fibromyalgia). Slightly more than $40 \%$ reported LBP, with three-fourths of those with LBP reporting radiating pain into the leg. Over $40 \%$ of respondents were taking oxycodone CR monotherapy (no oxycodone IR or other SAOs), and the majority was satisfied with oxycodone CR relieving their pain. However, most respondents taking oxycodone $\mathrm{CR}$ reported being bothered by side effects and taking less oxycodone $\mathrm{CR}$ than instructed because side effects were bothersome.

As the level of side-effect bother increased, MRU associated with side effects increased, specifically, physician calls, physician office visits, and prescription medications for managing side effects. The increased MRU observed in this study is associated with increased payer costs of $\$ 238$ per respondent per month. A retrospective private-payer claims study reported an incremental 3-month cost of $\$ 8,595$ per patient for health care services in the United States among noncancer patients initiating oxycodone or hydrocodone-containing IR therapy, who experienced and had a claim for nausea/vomiting. ${ }^{20}$ This equates to an average of $\$ 2,865$ per month, which is higher 
than the average payer costs per month of $\$ 609$ observed in this study among only those reporting MRU. This cost difference may be explained by the different lengths of time on the opioid (2.1 years in the present study compared with 3 months in the claims study). Some side effects, such as nausea and vomiting, usually develop early and sometimes resolve after tolerance to opioids develops; thus, the claims study may have higher MRU and costs because the population examined was newly initiated and may be less tolerant.

In 2009, a Drug Safety and Risk Management member of the U.S. Food and Drug Administration estimated there were 6.2 million prescriptions for oxycodone $\mathrm{CR}$, which could amount to substantial costs to payers for MRU associated with side effects of oxycodone CR. The findings of this study suggest that a payer in the United States could incur approximately $\$ 238,000$ per month for MRU associated with side effects for every 1,000 beneficiaries with a chronic noncancer pain condition treated with oxycodone CR.

\section{Limitations}

Foremost among the limitations, the likelihood of side effects, MRU, and associated costs may increase due to the severity of the respondent's underlying illness. However, significant differences in demographics and clinical characteristics between levels of side-effect bother were included in the regression models of MRU and costs to control for these relationships. In addition, other investigators have observed similar relationships between side effects, MRU, and costs in comparable noncancer populations, ${ }^{15,16}$ which suggests that the observed relationships may not be spurious. The likelihood of side effects, MRU, and associated costs also may increase depending on whether or not the subject is taking other opioids with a similar side-effect profile to oxycodone CR. To minimize this, respondents were asked in the survey to report only those side effects that they attributed to oxycodone CR; however, respondents may not be able to discern side effects attributable to oxycodone CR from those attributable to other opioids.

This survey study used a convenience sample, which may not be representative of the general population of patients with noncancer pain. Sampling error cannot be determined, so the reported results are exploratory. Additionally, the use of the Internet for recruiting survey respondents can impose bias. As of October 2009, only $73.5 \%$ of U.S. households had Internet access in the home; households with Internet access are more likely to be Caucasian or Asian, less than 65 years of age, employed, and have a higher level of education. ${ }^{21}$ Potential selection bias also may exist that underestimates side effects and associated MRU. All respondents were currently taking oxycodone CR; thus, the respondents did not include those who discontinued use because of unwanted side effects. On the other hand, survey respondents may reflect a population that had a less favorable experience, resulting in the overestimation of side effects and associated MRU. As a result, payer costs associated with side effect-related MRU may be overestimated or underestimated. Conservative assumptions were applied when assigning costs to MRU, and national average Medicare reimbursement rates were used, which are about 20\% to 30\% less than private payer reimbursement rates to physicians and hospitals, respectively. ${ }^{22}$

Multiple statistical tests were conducted in the analysis of MRU and costs across the severity levels of side-effect bother that were analyzed in this study; thus, the probability of making a type I error may be greater than 0.05 , which was used to assess statistical significance. One approach to adjust for multiple testing, besides the conservative Bonferroni adjustment approach, is to control for the false discovery rate, which aims at controlling the proportion of significant results that are type I errors. ${ }^{23}$ This alternative approach by Benjamini and Hochberg (1995) is sensible when the penalty of making even one type I error is not severe. ${ }^{24}$ This approach is being used in research that involves many tests, and when minimizing the probability of making one type I error, using other approaches can keep many true results from being detected. The significant results in this study did not change against a Benjamini and Hochberg significance level of 0.025 calculated for this study.

This study recruited adults with chronic noncancer pain, so these findings may not apply to adults with chronic cancer pain. Lastly, because this study recruited adults who were taking oxycodone CR, the incremental MRU and costs for respondents taking oxycodone CR compared with those not taking oxycodone CR cannot be calculated.

\section{Conclusions}

Among adults taking oxycodone CR for chronic noncancer pain (with or without neuropathic pain), over three-fourths reported being bothered by side effects. Respondents who reported higher levels of side-effect bother also reported greater MRU associated with side effects, including calls to their physicians, physician visits, and use of prescription medications for side effects, resulting in increased payer costs. The results of this study provide further support of the economic burden to payers associated with opioid-induced side effects in patients with chronic noncancer pain, with and without neuropathic pain. 


\section{Authors}

KATHRYN P. ANASTASSOPOULOS, MS, is Director and REBECCA BAIK, BS, is Senior Analyst, Health Economics and Outcomes Research, Covance Market Access Services Inc., Gaithersburg, Maryland. WING CHOW, MPH, PharmD, is Associate Director, Health Economics and Outcomes Research, and MYOUNG S. KIM, MBA, PhD, is Therapeutic Area Lead, Analgesics, U.S. Medical Affairs, Janssen Scientific Affairs, LLC, Raritan, New Jersey. CRISANTA I. TAPIA, MHS, is Senior Associate and STACEY J. ACKERMAN, MSE, PhD, is Vice President, Health Economics and Outcomes Research, Covance Market Access Services Inc., San Diego, California. DAVID BIONDI, DO, is Therapeutic Area Lead, Neuroscience, U.S. Medical Affairs, Janssen Scientific Affairs, LLC, Titusville, New Jersey.

AUTHOR CORRESPONDENCE: Kathryn P. Anastassopoulos, MS, Covance Market Access Services Inc., 9801 Washingtonian Blvd., 9th Fl., Gaithersburg, MD 20878. Tel.: 240.632.3304;

E-mail: kathryn.anastassopoulos@covance.com.

\section{DISCLOSURES}

This study was sponsored by Janssen Scientific Affairs, LLC. A related poster was presented at the Academy of Managed Care Pharmacy 2011 Educational Conference on October 20, 2011, in Atlanta, Georgia. Concept and design were contributed primarily by Chow, with assistance from Anastassopoulos and Kim and input from Tapia. Anastassopoulos, Biondi, Tapia, and Chow had primary responsibility for data collection, with input from Kim; data interpretation was primarily the work of Baik, with assistance from Ackerman and input from Anastassopoulos, Chow, and Biondi. The manuscript was primarily written by Anastassopoulos, with assistance from Tapia and input from Chow, Ackerman, Biondi, and Kim; its revision was the work of Anastassopoulos, with input from Baik, Chow, Tapia, and Ackerman.

\section{REFERENCES}

1. Institute of Medicine, Committee on Advancing Pain Research, Care, and Education. Relieving Pain in America: A Blueprint for Transforming Prevention, Care, Education, and Research. Washington, DC: The National Academies Press; 2011. Available at: http://www.iom.edu/Reports/2011/RelievingPain-in-America-A-Blueprint-for-Transforming-Prevention-Care-EducationResearch.aspx. Accessed September 16, 2012.

2. National Center for Health Statistics. Health, United States, 2006, with chartbook on trends in the health of Americans. Hyattsville, MD: 2006. Available at: http://www.cdc.gov/nchs/data/hus/hus06.pdf. Accessed September 16, 2012.

3. Freynhagen R, Baron R. The evaluation of neuropathic components in low back pain. Curr Pain Headache Rep. 2009;13(3):185-90.

4. Schmidt CO, Schweikert B, Wenig CM, et al. Modelling the prevalence and cost of back pain with neuropathic components in the general population. Eur J Pain. 2009;13(10):1030-35. Available at: http://onlinelibrary.wiley. com/doi/10.1016/j.ejpain.2008.12.003/abstract;jsessionid=9AC0B009F61426 F396CEC1CDEOD2B61F.d02t01. Accessed September 16, 2012.

5. Berger A, Dukes EM, Oster G. Clinical characteristics and economic costs of patients with painful neuropathic disorders. J Pain. 2004;5(3):143-49.

6. Slaton T, Benson C, Patel A, et al. Pain and adjuvant medication use among back and neck pain with or without neuropathic component and osteoarthritis patient. Poster presented at: 9th Annual American Society of Regional Anesthesia and Pain Medicine (ASRA) Pain Meeting \& Workshops. November 18-21, 2010; Phoenix, AZ.
7. Candiotti, KA, Gitlin MC. Review of the effect of opioid-related side effects on the undertreatment of moderate to severe chronic non-cancer pain: tapentadol, a step toward a solution? Current Med Res Opin. 2010;26(7):1677-84.

8. National Institutes of Health. NIH guide: mechanisms, models, measurement, \& management in pain research (R21). October 5, 2009. Available at: http://grants.nih.gov/grants/guide/pa-files/PA-10-007.html. Accessed September 16, 2012.

9. American Society of Anesthesiologists Task Force on Chronic Pain Management, American Society of Regional Anesthesia and Pain Medicine. Practice guidelines for chronic pain management: an updated report by the American Society of Anesthesiologists Task Force on Chronic Pain Management and the American Society of Regional Anesthesia and Pain Medicine. Anesthesiology. 2010;112(4):810-33. Available at: http://journals lww.com/anesthesiology/Fulltext/2010/04000/Practice_Guidelines_for_ Chronic_Pain_Management_.13.aspx. Accessed September 16, 2012.

10. Swegle JM, Logemann C. Management of common opioid-induced adverse effects. Am Fam Physician. 2006;74(8):1347-54.

11. Benyamin R, Trescot AM, Datta S, et al. Opioid complications and side effects. Pain Physician. 2008;11(2 Suppl):S105-S120.

12. OxyContin package insert. Purdue Pharma L.P. April 16, 2010. Available at: http://www.purduepharma.com/pi/prescription/oxycontin.pdf. Accessed September 16, 2012.

13. Friedmann N, Klutzaritz V, Webster L. Long-term safety of Remoxy (extended-release oxycodone) in patients with moderate to severe chronic osteoarthritis or low back pain. Pain Med. 2011;12(5):755-60.

14. Anastassopoulos KP, Chow W, Ackerman SJ, Tapia C, Benson C, Kim MS. Oxycodone related side effects: impact on degree of bother, adherence, pain relief, satisfaction, and quality of life. J Opioid Manag. 2011;7(3):203-15.

15. Kwong WJ, Diels J, Kavanagh S. Costs of gastrointestinal events after outpatient opioid treatment for non-cancer pain. Ann Pharmacother. 2010;44(4):630-40.

16. Iyer S, Davis KL, Candrilli S. Opioid use patterns and health care resource utilization in patients prescribed opioid therapy with and without constipation. Manag Care. 2010;19(3):44-51.

17. Hsiao WC, Braun P, Dunn D, Becker, ER. Resource-based relative values. An overview. JAMA. 1988;260(16):2347-53.

18. Red Book: Pharmacy's Fundamental Reference. 2010 ed. Montvale, NJ: Thomson Healthcare; 2010.

19. Radford A, Slifkin R, Fraser R, Mason M, Mueller K. The experience of sole community rural independent pharmacies with Medicare Part D: reports from the field. A Joint Publication of The North Carolina Rural Health Research \& Policy Analysis Center Working Paper No. 87 and The RUPRI Center for Rural Health Policy Analysis Policy Paper P2006-3. November 2006. Available at: http://www.shepscenter.unc.edu/rural/pubs/ report/WP87.pdf. Accessed September 16, 2012.

20. Kwong WJ, Diels J, Kavanagh S. Costs of gastrointestinal events after outpatient opioid treatment for non-cancer pain. Ann Pharmacother. 2010;44(4):630-40.

21. U.S. Census Bureau. Computer and Internet use in the United States: October 2009. Table 2. Available at: http://www.census.gov/hhes/computer/ publications/2009.html. Accessed September 16, 2012.

22. Sheils J, Haught R. The cost and coverage impacts of a public plan: alternative design options. Staff working paper \#4. The Lewin Group, Falls Church, VA, April 6, 2009. Available at: http://www.lewin.com/ /media/ lewin/site_sections/publications/lewin $\% 20$ cost $\% 20$ and $\% 20$ coverage $\% 20$ impacts $\% 20$ of\%20public\%20plan\%20alternative $\% 20$ design $\% 20$ options $\% 20$ final.pdf. Accessed September 16, 2012.

23. Verhoeven KJF, Simonsen KL, McIntyre LM. Implementing false discovery rate control: increasing your power. Oikos. 2005;108:643-47.

24. Benjamini Y, Hochberg Y. Controlling the false discovery rate: a practical and powerful approach to multiple testing. J R Stat Soc Series B. 1995;57(1):289-300. 